\title{
Seletividade do halosulfuron-methyl aplicado em pré-emergência da cultura da mamoneira
}

\author{
Renata L. M. da Silva ${ }^{1}$, Augusto G. F. Costa ${ }^{2}$, Valdinei Sofiatti ${ }^{2}$, Valeria V. Ribeiro ${ }^{3}$, \\ Cleber D. de G. Maciel $^{4}$ \& Danilo R. Monteiro ${ }^{5}$ \\ ${ }^{1}$ Pós-graduanda em Etnobiologia/Universidade Estadual da Paraíba. Campina Grande, PB. E-mail: renatalmsilva@gmail.com \\ ${ }^{2}$ Embrapa Algodão. Campina Grande, PB. E-mail: augusto.costa@embrapa.br (Autor correspondente); valdinei.sofiatti@embrapa.br \\ ${ }^{3}$ Departamento de Biologia/Universidade Estadual da Paraíba. Campina Grande, PB. E-mail: valeria_vr@hotmail.com \\ ${ }^{4}$ Departamento de Agronomia/Universidade Estadual do Centro-Oeste. Guarapuava, PR. E-mail: cmaciel@unicentro.br \\ ${ }^{5}$ Mestrando em Engenharia Agrícola/Universidade Federal Rural de Pernambuco. Recife, PE. E-mail: danilor.monteiro1@gmail.com
}

\section{Palavras-chave:}

herbicida

tolerância

Ricinus communis L.

plantio direto

\begin{abstract}
R E S U M O
A mamoneira é bastante sensível à competição, havendo necessidade de ampliar as alternativas de manejo de plantas daninhas, considerando-se principalmente as opções de herbicidas seletivos, visando favorecer a expansão das áreas de cultivo. O objetivo deste trabalho foi avaliar a seletividade do herbicida halosulfuron-methyl para a cultura da mamoneira aplicado em pré-emergência, antes da semeadura. Dois experimentos foram conduzidos em condições de casa-de-vegetação, um com solo arenoso e outro com francoargilo-arenoso, em delineamento inteiramente casualizado com quatro repetições. Os tratamentos se constituíram de cinco períodos entre a aplicação do herbicida e a semeadura $(0,7,14,21$ e 28 dias $)$ e uma testemunha sem aplicação. As avaliações realizadas foram: altura de plantas aos 7, 14, 21 e 28 dias após a emergência (DAE); diâmetro do caule, área foliar, volume de raízes, massa seca de parte aérea e raízes aos 28 DAE. Halosulfuron-methyl $\left(112,5 \mathrm{~g} \mathrm{ha}^{-1}\right)$ é seletivo para a cultura da mamoneira quando aplicado na modalidade de pré-emergência, antes da semeadura.
\end{abstract}

Key words:

herbicide

tolerance

Ricinus communis L.

no-tillage

\section{Selectivity of halosulfuron-methyl applied in preemergence of castor bean crop}

\footnotetext{
A B S T R A C T

Castor bean is very sensitive to competition, being necessary to expand the alternatives for weed management, principally considering the selective herbicide options, aiming to contribute to the expansion of the cultivated areas. The aim of this study was to evaluate the selectivity of the herbicide halosulfuron-methyl applied to castor bean crop in preemergence, before seeding. Two trials were conducted under greenhouse conditions, one with sandy and other with sandy clay loam soil, in a completely randomized design with four replications. The treatments corresponded to five periods between herbicide application and seeding $(0,7,14,21$ and 28 days $)$ and a control without application. The evaluations made were: plant height at 7, 14, 21 and 28 days after emergence (DAE); stem diameter, leaf area, root volume, dry mass of aerial part and roots at $28 \mathrm{DAE}$. Halosulfuron-methyl (112.5 $\left.\mathrm{g} \mathrm{ha}^{-1}\right)$ is selective to castor bean crop, when applied at preemergence modality, before seeding.
} 


\section{INTRODUÇÃO}

A mamoneira (Ricinus communis L.) é uma oleaginosa de importância econômica e social, de cujas sementes se obtém o óleo de rícino, as quais possuem excelentes propriedades, teor de óleo e largo uso como insumo industrial (Santos et al., 2007; Nass et al., 2007). Entretanto, nos sistemas de produção de mamona, como em qualquer cultura agrícola, a ocorrência de plantas daninhas está entre os principais fatores que interferem na produtividade, a qual pode ser reduzida em até $86 \%$ (Azevedo et al., 2006). Por possuir metabolismo fotossintético $\mathrm{C}_{3}$ e crescimento inicial lento (Azevedo et al., 2007), além do cultivo em espaçamentos largos na maioria das vezes, é pouco competitiva nos sistemas de produção geralmente adotados.

Para evitar a interferência das plantas daninhas o manejo utilizado tem sido, basicamente, o controle mecânico, utilizandose enxada ou cultivador, resultando em baixa eficiência e dependência de mão de obra, cada vez mais escassa e de custo elevado. Como alternativa, o controle químico é considerado o método mais prático e econômico (Maciel et al., 2008), havendo necessidade de aprimoramento dos programas de manejo de plantas daninhas (Sofiatti et al., 2012; Costa et al., 2014). Entretanto, poucas são as opções viáveis para o controle químico (Maciel et al., 2011), tornando imprescindíveis novos estudos que identifiquem herbicidas seletivos à mamoneira.

Entre as espécies de plantas daninhas a serem manejadas, a tiririca (Cyperus rotundus L.) é considerada a mais danosa e problemática, sobremaneira em virtude da elevada capacidade competitiva e de propagação (Dor \& Hershenhorn, 2013). Para esta espécie, o herbicida halosulfuron-methyl representa a principal opção, já tendo sido relatada sua seletividade por não resultar em redução no crescimento e promover fitotoxicidade à mamoneira, quando aplicado em pós-emergência (Silva et al., 2010). Este herbicida pertence ao grupo químico das sulfonilureias e possui, como mecanismo de ação, a inibição da enzima acetolactato sintase (ALS) e elevada eficácia de controle para espécies ciperáceas (Vitelli et al., 2010).

Apesar do indicativo da viabilidade técnica do halosulfuronmethyl aplicado em pós-emergência no cultivo da mamoneira (Silva et al., 2010; Costa et al., 2012), muitas vezes o nível de controle atingido nesta modalidade de aplicação pode não ser satisfatório, principalmente em áreas com elevados níveis de infestação inicial, exigindo outras estratégias. Outro agravante, no que se refere à aplicação após a emergência da cultura, se deve à recomendação desse herbicida no estádio de préflorescimento da tiririca (MAPA, 2013), podendo significar um controle tardio em virtude do estádio avançado de crescimento da planta daninha e da elevada sensibilidade da mamoneira à competição inicial. Desta forma, a aplicação de halosulfuronmethyl antes da semeadura na modalidade denominada como "dessecação" ou "manejo" poderia ser uma alternativa para reduzir previamente a infestação de tiririca, uma vez que os herbicidas utilizados nesta prática apresentam baixa eficiência no controle da espécie. Considerando como vantagem a seletividade, Souza et al. (2001) verificaram menores níveis de toxidez do halosulfuron-methyl ao algodoeiro, quando o mesmo foi aplicado antes da semeadura em relação à aplicação em pósemergência. No que se refere à eficácia, de acordo com Wehtje et al. (2006), o halosulfuron-methyl possui efeito sobre a tiririca não apenas pela absorção via foliar mas também pela atividade residual no solo. Walters \& Young (2010) constaram maior nível de controle de plantas daninhas [Digitaria ischaemum (Schreb. ex Shweig) Schreb. ex Muhl e Amaranthus retroflexus L.] e produtividade de abóbora (Curcubita pepo L.) quando os herbicidas clomazone+ethalfluralin foram associados ao halosulfuron-methyl em aplicação de pré-semeadura. Um dos fatores importantes que podem afetar a tolerância das culturas ao halosulfuron-methyl é sua persistência no ambiente edáfico. Sua degradação é maior com o aumento da temperatura e redução do $\mathrm{pH}$ do solo, sendo também influenciada pela umidade e textura, o que proporciona, ao herbicida, meia-vida, variando entre 7 e 98 dias (Dermiyati \& Yamamoto, 1997). Na solução do solo as moléculas de herbicida tendem a atingir equilíbrio entre a fase sorvida e a que permanece na solução porém a absorção pelas plantas, a eficácia e o transporte dependem, em grande parte, do equilíbrio entre os processos de sorção e dessorção. A sorção das sulfonilureias varia em função do conteúdo de matéria orgânica, $\mathrm{pH}$, textura e mineralogia dos solos (Oliveira et al., 2005). Rocha et al. (2013) consideram que existem poucos estudos sobre o comportamento de herbicidas em solos tropicais e que os resultados dessas pesquisas são de grande relevância para fazer recomendações seguras do ponto de vista técnico e ambiental. A persistência do herbicida no solo também influencia o período necessário entre a aplicação e a semeadura visando minimizar os prováveis efeitos fitotóxicos à cultura a ser implantada.

Para a cultura da mamoneira as pesquisas voltadas à seletividade dos herbicidas podem favorecer a ampliação de alternativas ou estratégias de controle de plantas daninhas, principalmente das espécies frequentes e de maior dificuldade de controle, razão pela qual o trabalho teve como objetivo avaliar a seletividade do herbicida halosulfuron-methyl utilizado na pré-emergência da cultura da mamoneira.

\section{Material e Métodos}

Dois experimentos foram conduzidos com a cultura da mamoneira em condições de casa-de-vegetação, localizada nas coordenadas $7^{\circ} 13^{\prime} 20^{\prime \prime} \mathrm{S}$ e $35^{\circ} 54^{\prime} 14^{\prime \prime} \mathrm{W}$, durante os meses de novembro e dezembro. Para cada ensaio foi utilizado um tipo de solo, originário da camada arável de áreas agrícolas em pousio nas localidades de Barbalha, CE, e Lagoa Seca, $\mathrm{PB}$. Amostras dos solos foram submetidas à análise química $\mathrm{e}$ física, cujos resultados estão apresentados na Tabela 1 .

Os solos utilizados como substratos foram peneirados em malha de $2 \mathrm{~mm}$, secados à sombra, adubados com $10 \mathrm{~kg}$ de superfosfato simples e $100 \mathrm{~g}$ de ureia por $\mathrm{m}^{-3} \mathrm{e}$, na sequência, utilizados para preencher vasos com capacidade de $2 \mathrm{~L}$, constituindo as unidades experimentais.

Os dois experimentos foram instalados em delineamento inteiramente casualizado com quatro repetições, para cada tipo de solo, cujos tratamentos foram representados por cinco períodos entre a aplicação do herbicida halosulfuron-methyl e a semeadura $(0,7,14,21$ e 28 dias $)$ e uma testemunha sem aplicação. Para manutenção da umidade adequada nos recipientes a partir do primeiro dia de aplicação até o final do período experimental, foi realizada irrigação diária por meio de um sistema composto por microaspersores com acionamento pré-programado por meio de um "timer". 
Tabela 1. Características físico-químicas de uma amostra dos solos utilizados nos experimentos

\begin{tabular}{|c|c|c|c|c|c|c|c|c|c|c|c|c|c|c|c|c|}
\hline \multirow{3}{*}{ Origem } & \multicolumn{12}{|c|}{ Características químicas } & \multicolumn{4}{|c|}{ Características físicas } \\
\hline & $\mathrm{pH}$ & $\mathrm{Ca}^{+2}$ & $\mathrm{Mg}^{+2}$ & $\mathrm{Na}^{+}$ & $\mathbf{K}^{+}$ & S & $\mathrm{H}+\mathrm{Al}$ & $\mathbf{T}$ & $\mathrm{Al}^{+3}$ & \multirow{2}{*}{$\begin{array}{l}\mathbf{V} \\
\%\end{array}$} & \multirow{2}{*}{$\underset{\mathrm{mg} \mathrm{dm^{-3 }}}{\mathbf{P}}$} & \multirow{2}{*}{$\begin{array}{l}\text { M.O. } \\
\mathrm{g} \mathrm{kg}^{-1}\end{array}$} & Areia & Silte & Argila & \multirow{2}{*}{ Classificação textural } \\
\hline & $\begin{array}{l}1: 2,5 \\
1,5\end{array}$ & \multicolumn{8}{|c|}{$\mathrm{mmol}_{\mathrm{c}} \mathrm{dm}^{-3}$} & & & & \multicolumn{3}{|c|}{ Granulometria $\left(\mathrm{g} \mathrm{kg}^{-1}\right)$} & \\
\hline Barbalha & 6,9 & 97,6 & 55,3 & 1,6 & 7,6 & 162,1 & 18,2 & 180,3 & ND & 89,9 & 11,9 & 20,7 & 536,0 & 245,1 & 218,9 & Franco-argilo-arenoso \\
\hline L. Seca & 6,1 & 14,4 & 5,4 & 0,4 & 1,2 & 21,4 & 15,7 & 37,1 & ND & 57,7 & 11,3 & 8,8 & 848,0 & 94,1 & 57,9 & Arenoso \\
\hline
\end{tabular}

${ }_{1}^{1} \mathrm{pH} \mathrm{H}_{2} \mathrm{O}$ - pH em água; $\mathrm{Ca}^{+2}$ - Cálcio; $\mathrm{Mg}^{+2}$ - Magnésio; $\mathrm{Na}^{+}$- Sódio; $\mathrm{K}^{+}$- Potássio; S - Soma de bases; H+Al - acidez potencial; T - Capacidade de troca catiônica; Al+3 - Alumínio; $\mathrm{V}$ - Saturação de bases; P - fósforo; MO - Matéria orgânica

O herbicida halosulfuron-methyl foi aplicado diretamente no solo úmido, antes da semeadura, na dose de 112,5 $\mathrm{g} \mathrm{ha}^{-1}$, conforme registro no Ministério da Agricultura, Pecuária e Abastecimento (MAPA) para o controle de Cyperus rotundus L. na cultura da cana-de-açúcar (MAPA, 2013). Para isto, utilizouse um pulverizador costal a pressão constante $\operatorname{com} \mathrm{CO}_{2}$, munido de barra com quatro pontas de pulverização de jato plano antideriva 11002 , espaçadas a $0,5 \mathrm{~m}$ entre si, posicionadas a 0,5 $\mathrm{m}$ de altura do alvo, com consumo de $200 \mathrm{~L}$ de calda ha ${ }^{-1}$. As aplicações ocorreram nos diferentes momentos correspondentes aos períodos antes da semeadura, de acordo com os tratamentos.

A cultivar utilizada foi a BRS Energia cujas sementes foram tratadas previamente com a mistura comercial dos fungicidas carboxina + tiram $\left(200+200 \mathrm{~g} \mathrm{~L}^{-1}\right)$ e o inseticida imidacloprido $\left(600 \mathrm{~g} \mathrm{~L}^{-1}\right)$, ambos na dose de $5 \mathrm{~mL}$ do produto comercial $\mathrm{kg}^{-1} \mathrm{de}$ semente. Todos os tratamentos foram semeados no mesmo dia, com três sementes por vaso, a $3,0 \mathrm{~cm}$ de profundidade, sendo o desbaste realizado cinco dias após a emergência das plântulas para permanência de uma planta por vaso. Durante o período experimental as unidades experimentais foram mantidas livres da presença de plantas daninhas por meio de controle manual para evitar o efeito de interferência das mesmas sobre o desenvolvimento das plantas de mamoneira.

Aos 7, 14 e 21 e 28 dias após a emergência (DAE), foram feitas avaliações da altura das plantas $(\mathrm{cm})$ obtida a partir da superfície do solo até a inserção da gema apical por meio de régua graduada.

Aos 28 DAE foram avaliados o diâmetro do caule, a área foliar, a biomassa seca da parte aérea, o volume e a massa seca do sistema radicular. O diâmetro do caule foi mensurado rente à superfície do solo utilizando-se um paquímetro digital. Obtevese a área foliar por estimativa, a partir das dimensões foliares, conforme método descrito por Severino et al. (2004). A biomassa seca da parte aérea e as raízes das plantas foram obtidas por secagem do material vegetal em estufa de ventilação forçada de ar, a $65^{\circ} \mathrm{C}$ pelo período de $72 \mathrm{~h}$ até alcançar massa constante, com posterior pesagem em balança semianalítica. $\mathrm{O}$ volume do sistema radicular foi determinado com base na metodologia descrita por Silva et al. (2006), na qual as raízes foram lavadas em água corrente e colocadas em uma proveta graduada com volume de $100 \mathrm{~mL}$, contendo $50 \mathrm{~mL}$ de água e, ao se adicionar as raízes, determinou-se o volume de água deslocada, valor este equivalente ao volume ocupado por essas raízes.

Os dados foram submetidos à análise de variância e as médias comparadas pelo teste Tukey a 0,05 de probabilidade.

\section{Resultados e Discussão}

Para as condições de semeadura da mamoneira em solo arenoso, em relação à altura de plantas de mamoneira avaliada aos 7, 14, 21 e 28 DAE (Tabela 2), assim como para as características diâmetro do caule, área foliar, volume de raízes, massa seca da parte aérea e de raízes, ao final do período experimental, não foi possível constatar efeito do halosulfuronmethyl, independente da época de aplicação (Tabela 3).

Nas aplicações em solo franco-argilo-arenoso, tal como ocorreu para o arenoso, não foi possível verificar interferência do halosulfuron-methyl na altura das plantas (Tabela 4), diâmetro do caule, área foliar, volume de raízes e massa seca da parte aérea e de raízes (Tabela 5), independente da época em que o herbicida foi aplicado. Considerando que o halosulfuron-methyl possui como mecanismo de ação a inibição da enzima acetolactato sintase (ALS), cujos sintomas resultantes são caracterizados por

Tabela 2. Efeito de halosulfuron-methyl em solo arenoso sobre a altura de plantas de mamoneira $(\mathrm{cm})$, aos 7, 14, 21 e 28 dias após a emergência (DAE)

\begin{tabular}{lcccc}
\hline \multicolumn{1}{c}{ Tratamento } & 7 DAE & 14 DAE & 21 DAE & 28 DAE \\
Sem aplicação & 9,13 & 11,00 & 12,37 & 12,62 \\
Aplicação 0 DAS & 7,13 & 9,62 & 10,75 & 11,25 \\
Aplicação 7 DAS & 8,63 & 10,75 & 11,12 & 11,37 \\
Aplicação 14 DAS & 9,38 & 12,37 & 12,62 & 13,12 \\
Aplicação 21 DAS & 9,50 & 11,62 & 12,00 & 12,00 \\
Aplicação 28 DAS & 8,38 & 10,25 & 10,87 & 11,50 \\
F & $2,60^{\text {ns }}$ & $1,76^{\text {ns }}$ & $1,68^{\text {ns }}$ & $1,15^{\text {ns }}$ \\
CV (\%) & 12,56 & 13,47 & 10,73 & 11,77 \\
\hline
\end{tabular}

DAS - Dias antes da semeadura; *Significativo a 0,05 de probabilidade; NSNão significativo

Tabela 3. Efeito do halosulfuron-methyl em solo arenoso sobre o diâmetro do caule, área foliar, volume do sistema radicular, massa seca de parte aérea e raízes de plantas de mamoneira, aos 28 dias após a emergência (DAE)

\begin{tabular}{|c|c|c|c|c|c|}
\hline \multirow{2}{*}{ Tratamento } & \multirow{2}{*}{$\begin{array}{l}\text { Diâmetro do caule } \\
(\mathrm{mm})\end{array}$} & \multirow{2}{*}{$\begin{array}{l}\text { Área foliar } \\
\left(\mathrm{cm}^{2}\right)\end{array}$} & \multirow{2}{*}{$\begin{array}{l}\text { Volume de raízes } \\
\qquad\left(\mathrm{cm}^{3}\right)\end{array}$} & \multicolumn{2}{|c|}{ Massa seca (g) } \\
\hline & & & & Parte aérea & Raízes \\
\hline Sem aplicação & 5,92 & 73,51 & 8,75 & 0,65 & 0,60 \\
\hline Aplicação 0 DAS & 5,92 & 115,19 & 7,33 & 0,96 & 0,46 \\
\hline Aplicação 7 DAS & 5,53 & 101,51 & 7,50 & 0,81 & 0,57 \\
\hline Aplicação 14 DAS & 6,28 & 111,65 & 9,75 & 0,94 & 0,72 \\
\hline Aplicação 21 DAS & 5,09 & 72,23 & 9,50 & 0,66 & 0,61 \\
\hline Aplicação 28 DAS & 6,10 & 103,01 & 7,00 & 0,71 & 0,53 \\
\hline $\mathrm{F}$ & $0,66^{\text {ns }}$ & $1,23^{\text {ns }}$ & $0,84^{\mathrm{ns}}$ & $0,81^{\text {ns }}$ & $1,82^{\text {ns }}$ \\
\hline CV $(\%)$ & 18,13 & 35,24 & 31,11 & 27,21 & 22,15 \\
\hline
\end{tabular}

DAS - Dias antes da semeadura; *Significativo a 0,05 de probabilidade; "NSNão significativo 
Tabela 4. Efeito de halosulfuron-methyl em solo francoargilo-arenoso sobre a altura $(\mathrm{cm})$ de plantas de mamoneira, aos 7, 14, 21 e 28 dias após a emergência (DAE)

\begin{tabular}{lcccc}
\hline Tratamento & 7 DAE & 14 DAE & 21 DAE & 28 DAE \\
Sem aplicação & 7,65 & 11,75 & 13,25 & 14,62 \\
Aplicação 0 DAS & 9,75 & 12,16 & 13,00 & 13,83 \\
Aplicação 7 DAS & 8,62 & 11,87 & 14,62 & 15,25 \\
Aplicação 14 DAS & 8,00 & 11,75 & 12,37 & 13,87 \\
Aplicação 21 DAS & 8,66 & 12,16 & 14,16 & 15,16 \\
Aplicação 28 DAS & 7,87 & 11,87 & 13,00 & 14,50 \\
F & $0,84^{\text {ns }}$ & $0,33^{\text {ns }}$ & $0,43^{\text {ns }}$ & $0,18^{\text {ns }}$ \\
CV (\%) & 19,95 & 17,64 & 18,84 & 19,55 \\
\hline
\end{tabular}

DAS - Dias antes da semeadura; *Significativo a 0,05 de probabilidade; NSNão significativo

interrupção do crescimento, clorose de folhas novas, necrose de tecidos e morte das regiões meristemáticas, podendo ser visíveis a partir da primeira ou segunda semana após a aplicação (Nicolai et al., 2008), ressalta-se que em ambos os ensaios não foi possível constatar qualquer um desses sintomas, seja em relação ao crescimento, por meio de todas as avaliações quantitativas realizadas, ou mesmo visualmente, durante o período experimental.

Apesar de não ter sido constatado efeito do tempo entre a aplicação e a semeadura sobre toxidez do halosulfuron-methyl à mamoneira, alguns trabalhos mostraram resultados neste sentido com outras culturas. Souza et al. (2001) constataram maior nível de redução na área foliar da cultura do algodoeiro (46\%) quando a aplicação do halosulfuron-methyl foi realizada aos 2 DAS, em relação às aplicações realizadas aos 15 e 30 DAS, as quais resultaram em 14\% de diminuição. Guerra et al. (2011) constataram, ao estudar herbicidas inibidores da enzima ALS (tryfloxysulfuron-sodium ou pyriothiobac-sodium), maior fitointoxicação da planta indicadora (pepino) quando as semeaduras foram realizadas mais próximas do momento da aplicação desses herbicidas.

Ao considerar as características químicas e físicas dos solos sobre a seletividade de herbicidas, Vivian et al. (2007) mencionam que geralmente se verifica, em solos com altos teores de argila, de matéria orgânica ou em ambos, maior adsorção e persistência dos herbicidas. Deve-se destacar, porém, que a quantidade de matéria orgânica do solo tem, em razão da sua alta capacidade de troca de cátions e grande superfície específica, papel fundamental na adsorção de herbicidas. Sua influência nas propriedades físico-químicas passa a ser ainda maior nos solos tropicais, haja vista que estes possuem predominantemente minerais de argila de baixa atividade. Adicionalmente, mesmo os minerais 2:1, como vermiculita e montmorilonita, apresentam efeito menor sobre a adsorção de herbicidas em relação à matéria orgânica (Oliveira \& Brighenti, 2011).
Grey \& McCullough (2012) ainda reportam que os herbicidas do grupo das sulfonilureias, do qual faz parte o halosufuron-methyl, são fracamente adsorvidos pelos minerais de argila mas possuem, em geral, atividade inversamente proporcional ao teor de matéria orgânica. Além disso e se considerando que o halosulfuron-methyl também pode ser absorvido pelas raízes, apesar da via principal ser a foliar (Wehtje et al., 2006), no presente estudo, mesmo o solo franco-argilo-arenoso possuindo 2,4 e 3,8 vezes mais matéria orgânica e argila que o solo arenoso, respectivamente, não foi possível verificar interferência do herbicida sobre o crescimento da mamoneira, em nenhum dos ensaios.

Em aplicações de pós-emergência com halosulfuron-methyl (112 $\left.\mathrm{g} \mathrm{ha}^{-1}\right)$, Silva et al. (2010) também não constataram reduções sobre as características altura de plantas, diâmetro do caule e área foliar. Costa et al. (2012) também não observaram efeito negativo do halosulfuron-methyl sobre a altura de plantas e diâmetro do caule nem, tampouco, na massa seca de raízes. Os níveis obtidos nas avaliações visuais de fitointoxicação foram considerados baixos em ambos os trabalhos. Somando esses resultados aos do presente estudo, nos quais não se constatou efeito negativo do herbicida aplicado antes da semeadura da mamoneira, é corroborada a hipótese de que a mamoneira seja considerada tolerante ao halosulfuron-methyl. Desta forma, a aplicação em pré-emergência representa, na pré-semeadura, alternativa de uso para o halosulfuron-methyl, possibilitando a ampliação de estudos de seletividade para o aprimoramento do manejo de plantas daninhas na cultura da mamoneira, especialmente em áreas com elevada infestação de tiririca.

\section{Conclusão}

O halosulfuron-methyl (112,5 $\left.\mathrm{g} \mathrm{ha}^{-1}\right)$ aplicado em préemergência, antes da semeadura, é seletivo à cultura da mamoneira.

\section{Agradecimentos}

Ao Conselho Nacional de Desenvolvimento Científico e Tecnológico (CNPq) pela Bolsa de Iniciação Científica (PIBIC) concedida ao primeiro autor.

\section{Literatura Citada}

Azevedo, D. M. P. de; Beltrão, N. E. de M.; Severino, L. S.; Cardoso, G. D. Controle de plantas daninhas. In: Azevedo, D. M. P. de; Beltrão, N. E. de M. O agronegócio da mamona no Brasil. 2.ed. Brasília: Embrapa Informação Tecnológica, 2007. p.335-359.

Tabela 5. Efeito do halosulfuron-methyl em solo franco-argilo-arenoso sobre o diâmetro do caule, área foliar, volume do sistema radicular, massa seca de parte aérea e raízes de plantas de mamoneira, aos 28 dias após a emergência (DAE)

\begin{tabular}{|c|c|c|c|c|c|}
\hline \multirow{2}{*}{ Tratamento } & \multirow{2}{*}{$\begin{array}{l}\text { Diâmetro do caule } \\
(\mathrm{mm})\end{array}$} & \multirow{2}{*}{$\begin{array}{l}\text { Área foliar } \\
\left(\mathrm{cm}^{2}\right)\end{array}$} & \multirow{2}{*}{$\begin{array}{l}\text { Volume de raízes } \\
\qquad\left(\mathrm{cm}^{3}\right)\end{array}$} & \multicolumn{2}{|c|}{ Massa seca (g) } \\
\hline & & & & Parte aérea & Raízes \\
\hline Sem aplicação & 6,63 & 179,73 & 5,00 & 1,40 & 0,43 \\
\hline Aplicação 0 DAS & 6,25 & 137,72 & 4,33 & 0,86 & 0,42 \\
\hline Aplicação 7 DAS & 6,46 & 220,06 & 6,75 & 1,42 & 0,55 \\
\hline Aplicação 14 DAS & 6,66 & 175,32 & 4,67 & 1,09 & 0,40 \\
\hline Aplicação 21 DAS & 6,99 & 212,14 & 4,00 & 1,56 & 0,44 \\
\hline Aplicação 28 DAS & 6,95 & 237,06 & 7,00 & 1,71 & 0,69 \\
\hline $\mathrm{F}$ & $0,23^{\text {ns }}$ & $0,84^{\text {ns }}$ & $1,77^{\mathrm{ns}}$ & $0,95^{\mathrm{ns}}$ & $1,09^{\text {ns }}$ \\
\hline CV (\%) & 17,59 & 40,96 & 36,21 & 48,16 & 44,74 \\
\hline
\end{tabular}

DAS - Dias antes da semeadura; ${ }^{*}$ Significativo a 0,05 de probabilidade; NsNão significativo 
Azevedo, D. M. P. de; Santos, J. W. dos; Santos, T. S.; Leão, A. B. Período crítico de competição entre mamoneira e plantas daninhas. Revista Brasileira de Oleaginosas e Fibrosas, v.10, p.1017-1024, 2006.

Costa, A. G. F.; Sofiatti, V.; Maciel, C. D. G.; Poletine, J. P.; Sousa, J. I. Weed management strategies for castor bean crops. Acta Scientiarum Agronomy, v.36, p.135-145, 2014. http://dx.doi. org/10.4025/actasciagron.v36i2.17090

Costa, A. G. F.; Sofiatti, V.; Silva, D. R. D. S. Seletividade de herbicidas pós-emergentes à mamoneira para o controle de ciperáceas. In: Congresso Brasileiro de Mamona, 5, Simpósio Internacional de Oleaginosas e Energéticas, 2, 2012, Guarapari. Anais... Guarapari: Embrapa Algodão, 2012. CD-Rom

Dermiyati, S. K.; Yamamoto, I. Degradation of the herbicide halosulfuron-methyl in two soils under different environmental conditions. Journal of Pesticide Science, v.22, p.282-287, 1997. http://dx.doi.org/10.1584/jpestics.22.282

Dor, E.; Hershenhorn, J. Effect o low temperature on purple nutsedge (Cyperus rotundus) reproductive biology. Weed Science, v.61, p.239243, 2013. http://dx.doi.org/10.1614/WS-D-12-00061.1

Grey, L. T.; Mccullough, P. E. Sulfonylurea herbicides' fate in soil: Dissipation, mobility, and other processes. Weed Technology, v.26, p.579-581, 2012. http://dx.doi.org/10.1614/WT-D-11-00168.1

Guerra, N.; Oliveira Júnior; R. S.; Constantin, J.; Oliveira Neto, A. M.; Santos, G.; Jumes, T. M. C. Persistência de trifloxysulfuronsodium e pyrithiobac-sodium em diferentes tipos de solo. Planta Daninha, v.29, p.673-681, 2011. http://dx.doi.org/10.1590/S010083582011000300022

Maciel, C. D. G.; Poletine, J. P.; Velini, E. D.; Amaral, J. G. C.; Zani, L. P.; Santos, R. F.; Rodrigues, M.; Raimondi, M. A.; Ribeiro, R. B. Possibilidade de aplicação de misturas de herbicidas de ação total com jato dirigido em mamoneira de porte anão. Planta Daninha, v.26, p.457-464, 2008. http://dx.doi.org/10.1590/S010083582008000200023

Maciel, C. D. G.; Silva, T. R. B.; Poletine, J. P.; Velini, E. D.; Zanotto, M. D.; Martins, F. M.; Gava, F. Seletividade e eficácia de herbicidas inibidores da enzima ACCase na cultura da mamona. Planta Daninha, v.29, p.609-616, 2011. http://dx.doi.org/10.1590/S010083582011000300015

MAPA - Ministério da Agricultura, Pecuária e Abastecimento. Agrofit. http://extranet.agricultura.gov.br/agrofit_cons/principal_agrofit_ cons. 12 Mar. 2013.

Nass, L. L.; Pereira, P. A. A.; Ellis, D. Biofuels in Brazil: An overview. Crop Science, v.47, p.2228-2237, 2007. http://dx.doi.org/10.2135/ cropsci2007.03.0166

Nicolai, M.; Christoffoleti, P. J.; Vargas, L. Resistência de plantas daninhas aos herbicidas inibidores da ALS (Grupo B). In: Christoffoleti, P. J. Aspectos de resistência de plantas daninhas a herbicidas. Piracicaba: HRAC, 2008. p.35-49.
Oliveira, M. F.; Brighenti, A. M. Comportamento de herbicidas no ambiente. In: Oliveira Júnior, R. S.; Constantin, J.; Inoue, M. H (ed.). Biologia e manejo de plantas daninhas. Curitiba: Omnipax, 2011. p.263-304.

Oliveira, M. F.; Prates, H. T.; Sans, L. M. A. Sorção e hidrólise do herbicida flazasulfuron. Planta Daninha, v.23, p.101-113, 2005. http://dx.doi.org/10.1590/S0100-83582005000100013

Rocha, P. R. R.; Faria, A. T.; Borges, L. G. F. C.; Silva, L. O. C.; Silva, A. A.; Ferreira, E. A. Sorção e dessorção do diuron em quatro solos brasileiros. Planta Daninha, v.31, p.231-238, 2013. http://dx.doi. org/10.1590/S0100-83582013000100025

Santos, R. F.; Kouri, J.; Barros, M. A. L.; Marques, F. M.; Firmino, P. T.; Requião, L. E. G. Aspectos econômicos do agronegócio da mamona. In: Azevedo, D. M. P. de; Beltrão, N. E. de M. O agronegócio da mamona no Brasil. 2.ed. Brasília: Embrapa Informação Tecnológica, 2007. p.21-41.

Severino, L. S.; Cardoso, G. D.; Vale, L. S.; Santos, J. W. dos. Método para determinação da área foliar da mamoneira. Revista Brasileira de Oleaginosas e Fibrosas, v.8, p.73-72, 2004.

Silva, M. T. H.; Martins, A. B. G.; Andrade, R. A. Enraizamento de estacas de pitaya vermelha em diferentes substratos. Caatinga, v.19, p.61-64, 2006.

Silva, V. N. B.; Silva, F. M. O.; Sofiatti, V.; Silva, K. C.; Silva, D. M. Tolerância da cultura da mamoneira ao herbicida halosulfuron. In: Congresso Brasileiro de Mamona, 4, Simpósio Internacional de Oleaginosas e Energéticas, 1, 2010, João Pessoa. Anais... João Pessoa: Embrapa Algodão, 2010. CD-Rom

Sofiatti, V.; Severino, L. S.; Silva, F. M. O.; Silva, V. N. B.; Brito, G. G. Pre and postemergence herbicides for weed control in castor crop. Industrial Crops and Products, v.37, p.235-237, 2012. http://dx.doi. org/10.1016/j.indcrop.2011.12.019

Souza, L. S.; Martins, D.; Camposilvan, D.; Velini, E. D.; Palma, V. Seletividade do halosulfuron isolado ou em mistura com glyphosate para culturas anuais. Planta Daninha, v.19, p.351-358, 2001. http:// dx.doi.org/10.1590/S0100-83582001000300007

Vitelli, J. S.; Madigan, B. A; Haaren, P. E. van. Control techniques and management strategies for the problematic Navua sedge (Cyperus aromaticus). Invasive Plant Science and Management, v.3, p.315326, 2010. http://dx.doi.org/10.1614/IPSM-D-09-00036.1

Vivian, R.; Guimarães, A. A.; Queiroz, M. E. L. R.; Silva, A. A.; Reis, M. R.; Santos, J. B. Adsorção e dessorção de tryfloxysulfuron-sodium e ametryn em solos brasileiros. Planta Daninha, v.25, p.97-109, 2007. http://dx.doi.org/10.1590/S0100-83582007000100011

Walters, S. A.; Young, B. G. Effect of herbicide and cover crop on weed control in no-tillage jack-o-lantern pumpkin (Curcubita pepo L.) production. Crop Protection, v.29, p.30-33, 2010. http://dx.doi. org/10.1016/j.cropro.2009.09.001

Wehtje, G. R.; Gilliam, C. H.; Grey, T. L.; Blythe, E. K. Potential for halosulfuron to control eclipta (Eclipta prostrata) in containergrown landscape plants and its sorption to container rooting substrate. Weed Technology, v.20, p.361-367, 2006. http://dx.doi. org/10.1614/WT-05-063R.1 